\title{
Spatial simulation environment for decision support
}

\author{
J. Forster ${ }^{1}$, S. Fritz ${ }^{2} \&$ N. Rab ${ }^{2}$ \\ ${ }^{1}$ Department of Spatial Planning, Simlab, \\ Vienna University of Technology, Austria \\ ${ }^{2}$ Institute of Energy Systems and Electrical Drives, \\ Energy Economics Group, Vienna University of Technology, Austria
}

\begin{abstract}
The city of Vienna (Austria) follows a long-term initiative to be sustainable and affordable. This initiative is getting increasingly difficult due to a changing energy landscape and the aim to increase the usage of renewable energies. Additionally Vienna is a growing city. Current population forecasts predict a growth of the population which will pass the two million mark within 2029. Thus the requirements on space, infrastructure and support systems and therefore planners and decision makers are increasing. Concerning these issues, the paper focuses on the city's internal development potential as a basis for gaining new living and working areas. A model calculating the floor-area potential considering city development areas will be presented. This model establishes a basis for a simulation environment which is expandable via heating system models. The simulation environment is needed to test and visualize future scenarios. Thus it acts as an interactive, multi-scalar decision and planning support tool for interdisciplinary stakeholders. This generic approach aims to describe a process tool with the ability to be used in other cities and other disciplines.

Keywords: cooperative tool, decision support tool, 3D city model, simulation environment, spatial planning, energy planning.
\end{abstract}




\section{Introduction}

\subsection{Motivation}

Vienna's population expanded by $9.1 \%$ in the last decade, which is equal to about 144,000 persons. Actual population forecasts predict a continuation of this trend. Therefore Vienna will reach the 2 million mark within 2029 [1, preamble]. This intense growth accompanies big challenges on several utility levels (e.g. flats, jobs, mobility systems, utility networks, ... ). Moreover the city of Vienna (Austria) follows a long-term initiative of becoming a Smart City. Thus efficient, affordable and low-carbon energy systems, as well as environmentfriendly transport systems are obligatory. They provide sustainable development and better urban functionalities in cities.

Likewise the supply with needed living and working areas of a growing city is a complex challenge for the planners. To guide a city into a sustainable future the economical usage of ground resources constitutes the base for resilient settlement development.

The calculation and spatial location of potential areas for inner development within the city limits is the basis for decision and planning processes. These involve interdisciplinary stakeholders. For these processes 3D models are useful support tools and enable a multi level procedural access to problem solving strategies. Furthermore the virtual models enable the possibility to visualize functions and behaviours of visible and invisible objects in reality. Moreover different fields of research can be implemented and calculation results interconnected. Hence the combination of different models within one simulation environment constitutes a decision and planning support tool as well as a cooperative planning instrument.

\subsection{Research question}

This approach addresses the following research questions: How can inner development potential become spatially located and integrated in a three dimensional simulation environment? And how can it consider the complex challenges in urban planning with common interdisciplinary fields to design a decision support tool for various stakeholders and policy makers?

\subsection{State of the art}

The premise "Inner development before outer development constitutes a short formula for sustainable spatial development" [2, p. 3] should be maintained, means to evaluate and design the need of develop-able ground in growing cities within the existing city limits. Thus the project "Raum+" is developed by the ETH Zürich since 2008, which constitutes a method to locate the inner development potential for various cantons in Switzerland to reach an quantitative and qualitative overview 
(cf. [3]). This enables targeted development strategies and launches new spatial planning processes for the mobilization of existing reserves in settlement areas

The aim to support such planning processes with the use of visual medias and three dimensional city models is focused in various projects over the globe. They are mostly focusing on topics concerning sustainability and ecological aspects.

Likewise, the ETH Zürich in collaboration with IBM, ESRI and the Imperial College London, developed a project named "Smart Urban Adapt". This project aims to support "European cities with next-generation decision tools, to design development paths for the 1-ton-CO2-society" [4]. The scenario based project was developed between 2012 and 2013 and handles a cloud based decision support tool for urban planning as well as interactive climate and land use prediction. In this regard they created smart sensing data connections to an implemented GIS data warehouse, which enables spatial visualizations (cf. [4]).

In 2014 a five dimensional data platform for cities with an implemented visual environment was introduced by "Cityzenith" (cf. [5]). The main focus is to allow access to different kinds of data for a broad bandwidth of people.

All these projects support planners and stakeholders through software environments which enable data handling, data exchange and visualization environments. Thus 3D models are useful tools for procedural planning processes or problem solving strategies in planning environments (like those based on trainings and formulated by Walther Schönwandt (cf. [6]).

On the one hand these simulation environments can support planning processes, and on the other hand they have the ability to flag problems.

\section{Methodological framework}

\subsection{Inner development tracking model}

The aim to achieve space-saving settlement development and to gain building sites located within the city limits, is a indisputable strategy for sustainable urban development. Thus irreversible surface sealing connected to hardly inestimable subsequent costs (drainage, ...) and unnecessary extension of existing infrastructure (transport, supply infrastructure, ...) avoiding higher costs, higher energy demand and environmental pollution are avoidable or controllable.

Following the abstract concept of the "Raum+" project in Switzerland (cf. Section 1.3) this approach distinguishes between floor-area-potential and building-area-potential (cf. Fig. 1). The term floor-area-potential defines the potential of additional floors on existing buildings available within the legal restrictions. The Building-area-potential defines available empty building sites, and developed real estates with potential of additional constructions within the legal restrictions.

This approach explains a method for the calculation and spatial location of floorarea potential based on GIS data sets, containing building information (shape, relative height) and legal restrictions including the area category. The area category is a basement map of Vienna which determines area usage and the maximum cullis 


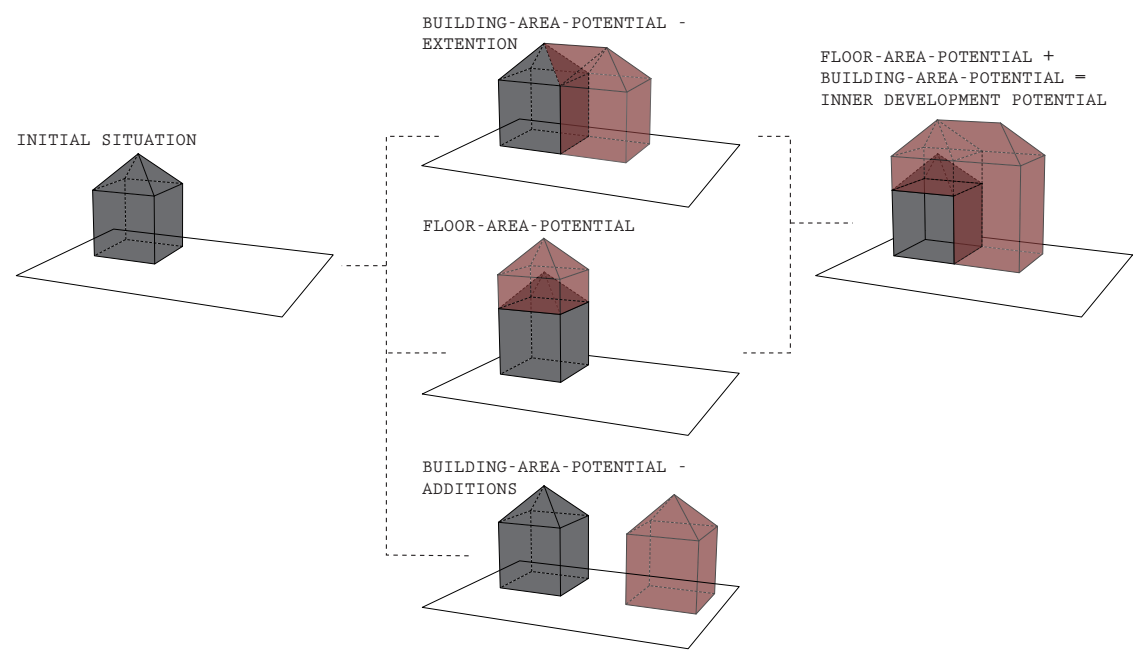

Figure 1: Inner development differentiations (own illustration).

height of a building. All these data sets are provided by the municipal department 41 of the city of Vienna in the context of the doctoral college URBEM (Urban Energy and Mobility Systems) executed by the Vienna University of Technology.

The building-area potentials of new urban development areas are visualized in an abstract form within the urban development plan 2025 published by the municipal department 18 - urban development and urban planning in 2014 (cf. [7]). Overlaying these two layers of inner development potentials constitutes the basis for a spatial analysis of available areas for the development of living and work spaces.

To calculate an overview of the theoretical floor-area-potential $\left(h_{\mathrm{pot}}^{i}\right)$ the built height of a building $\left(h_{\text {stock }}^{i}\right)$ is subtracted from licensed maximum building height $\left(h_{\max }^{i}\right)$ :

$$
h_{\mathrm{pot}}^{i}:=h_{\max }^{i}-h_{\mathrm{stock}}^{i} .
$$

If a building is extended by one level, a minimal construction height of $3.5 \mathrm{~m}$ is assumed. For each further level this construction height (gh) can be reduced by the following assumption:

$$
h_{\mathrm{pot}}^{i}:=\left\{\begin{array}{lll}
g h=3.5 & \text { if } & h_{\mathrm{pot}}^{i}<6.4 \\
g h=3.2 & \text { if } & h_{\mathrm{pot}}^{i} \geq 6.4 \text { and } h_{\mathrm{pot}}^{i}<9, \\
g h=3 & \text { if } & h_{\mathrm{pot}}^{i} \geq 9 .
\end{array}\right.
$$




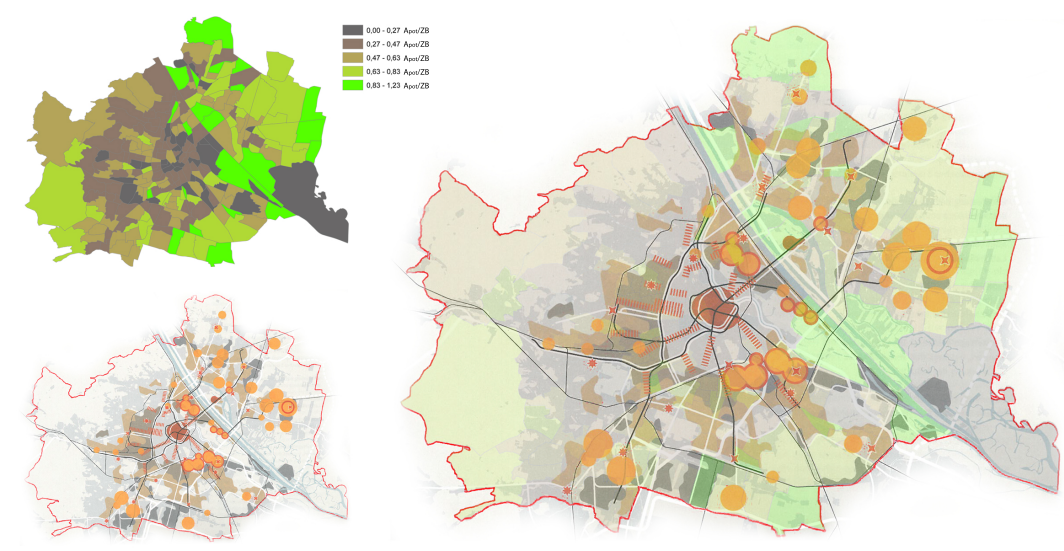

Figure 2: (a) Overview of inner development potential on registration district level; (b) Potential development areas within the city of Vienna (source: [7, p.67]); (c) Overlay of (a) and (b) for a procedural matching of floor area potentials and possible potentials of new building areas.

Thus the floor-area-potential $\left(A_{\mathrm{pot}}^{i}\right)$ is calculated as follows $\left(G_{\text {stock }}^{i}=\right.$ building basement area):

$$
A_{\mathrm{pot}}^{i}:=\left\{\begin{array}{cl}
\left\lfloor\frac{h_{\mathrm{pot}}^{i}}{h g}\right\rfloor G_{\mathrm{stock}}^{i} & \text { if } \quad G_{\mathrm{stock}}^{i} \geq 10 \mathrm{~m}^{2}, \\
0 & \text { else. }
\end{array}\right.
$$

To locate these calculation results spatially and generate an overview map the output is visualized on registration district level (ZB) and classified in five intervals:

$$
A_{\mathrm{pot}} / Z B=\sum_{i=1}^{\infty} A_{\mathrm{pot}}^{i} / \sum_{i=1}^{\infty} G_{\mathrm{stock}}^{i}
$$

For Vienna these results are between 0 and 1,23 $\left(A_{\text {pot }} / Z B\right)$. The overview map (cf. Fig. 2(a)) illustrates the main floor-area-potential in the northeast, south and west city outskirts. These areas are mostly loosely built by single family houses and small apartment buildings. However some floor-area-potentials calculated by the described method are located near the city center where houses built in the years of rapid industrial expansion("Gründerzeit" houses) as well as other buildings in enclosed construction are located.

This inner development model constitutes no detailed statement of all inner development potentials, but enables the detection of inner city development areas 
of spatial interest. In general this overview represents the basis for a multi scalar approach, zooming city quarters incrementally.

Selected city quarters are forwarded to the simulation environment. Within this environment a spatial overlay with the output of (for example) the Heating Energy System Model [8] is enabled. Thus strategies are evaluated of central or decentralized heat and energy supply as well as the use of solar heat (by computing specific economic and ecologic indicators) for the entire heating system.

\subsection{Setting up the decision support tool}

For the composition of a multi-scale planning and decision support tool for interdisciplinary participants, the calculation output data (tables) of a developed model of any interdisciplinary field can be joined by ID numbers via GIS software to corresponding object shapes. Thus the two dimensional GIS data sets are able to be transformed in three dimensional objects with rule based procedural 3D modeling Software (this approach uses ESRI City Engine). Thereby an abstract virtual city model has evolved. Next this virtual model is imported in a software for game development (this approach uses UNITY). Within this software an executable simulation can be generated, allowing to change single objects visual appearance (color, size and position) via defined intervals corresponding to the data it represents (changes available via a Graphical User Interface). The models of various disciplines are connected as modules within the simulation environment. Thus each spatial model can be developed independently with regard to its content. For fully automated dynamical data exchange and/or extension, the modules are connected via a cloud based data platform. This data platform enables the degree of abstraction for each single data transfer and data set which is important for the comprehensiveness of the information visualization as well as for security reasons.

Furthermore a graphical user interface for the interactive handling of predefined control parameters within testing and decision processes is designed. Finally the environment allows the use of various users simultaneously and interactive user control.

The main structure of the described simulation environment and the directions of the interdisciplinary data streams are illustrated in Fig. 3.

\section{Results}

The simulation environment is able to represent the connection between researchers and stakeholders, in particular the public and governance. It illustrates the research results and communicates new findings and ideas to a broad bandwidth of people. Moreover it is able to cover different areas of expertise, several levels of detail as well as different time horizons and areas.

The following figures present a prototype area at the border of the eighth and sixteenth Viennese district (Vienna Beltway - Lerchenfelder Gürtel). Within this prototype the floor area potential of the existing building is shown. Furthermore 


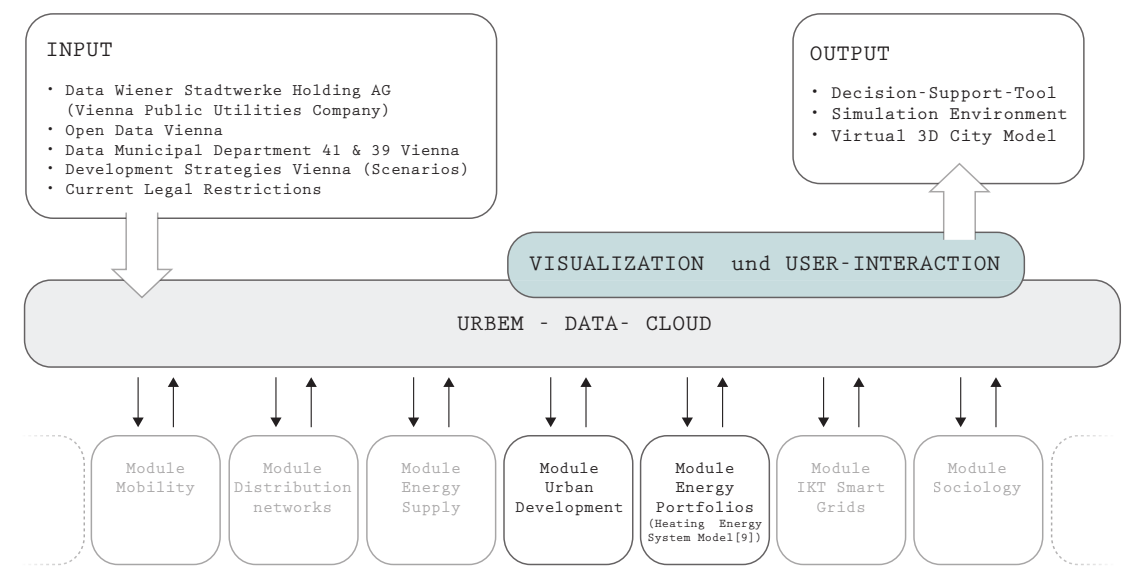

Figure 3: Simulation environment structure. (Source: Own illustration following [4].)

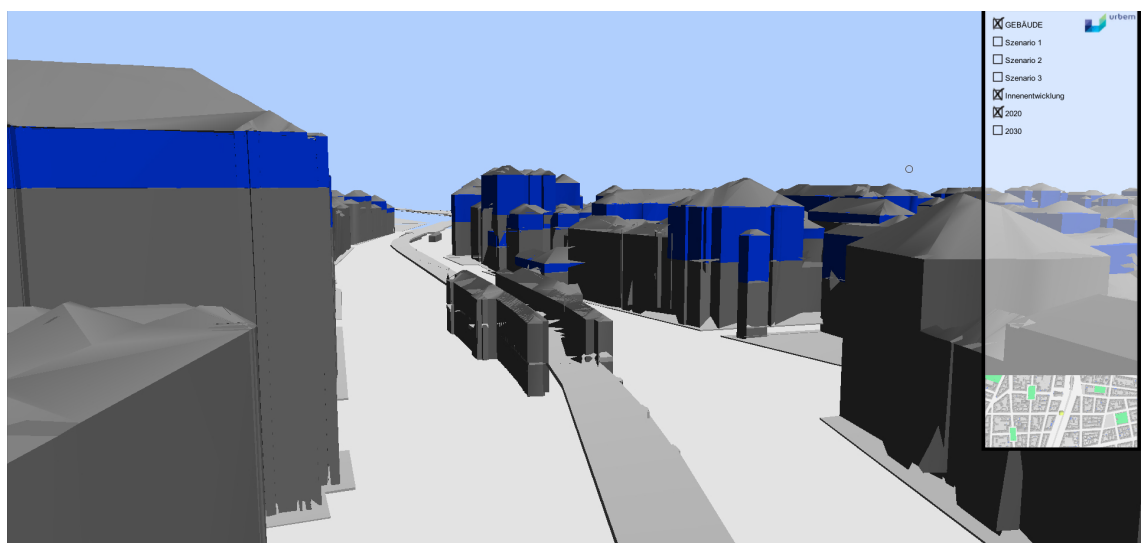

Figure 4: Prototype Area Vienna Beltway: Inner development potentials (blue coloured). (Source: Own illustration.)

it displays the output data of the Heat and Energy System Model. This shows the probability for installed solar heat units for 2020 and 2030.

The developed multi dimensional visualization can be presented within a back-projection environment with a stereoscopic view for up to 15 participants simultaneously. Furthermore for individual investigations or cooperation of participants at different locations an Virtual Reality Headset with 3D viewing options (Oculus Rift) integration is possible. 


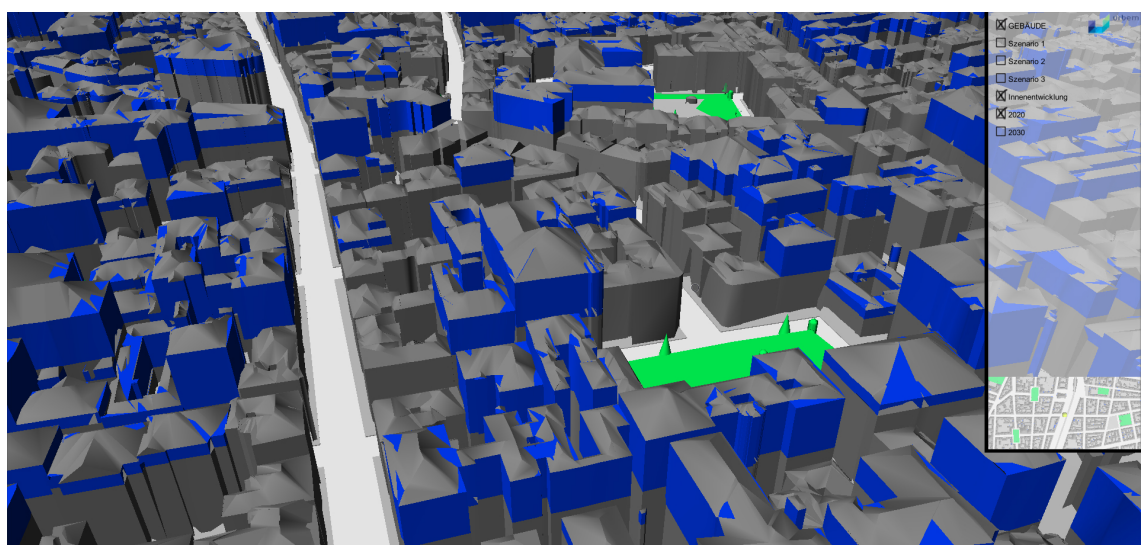

Figure 5: Prototype Area Vienna Beltway: Inner development potentials (blue coloured). (Source: Own illustration.)

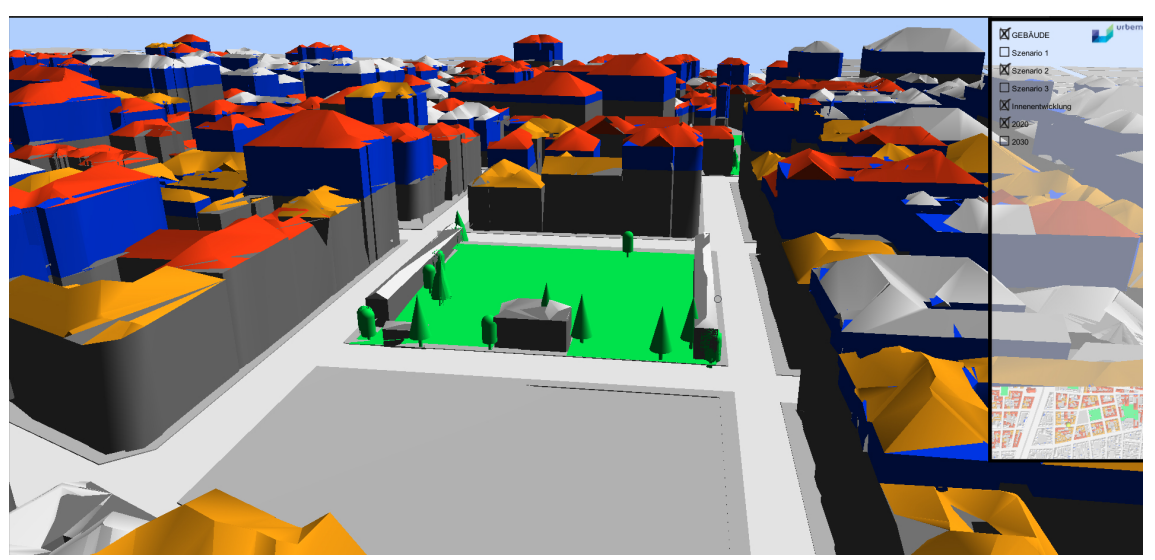

Figure 6: Prototype Area Vienna Beltway: Inner development potentials and visual data representation of the Heating Energy System Model [8]. (Source: Own illustration.)

\section{Discussion and conclusion}

The connection of interdisciplinary models within one simulation as well as the connection of individual objects within these models enables a broad tool for analysis and testing. It allows the virtual visualization of future scenarios in urban systems. This method constitutes a helpful tool to gain new knowledge and interweaves disciplines seemingly unconnected. 
The connection of the interdisciplinary models via a cloud based data base emerged as a good solution for the data exchange, because of automatized synchronization. Thereby connecting the virtual built objects in the three dimensional simulation model with the associated data via IDs turned out very useful for the bridge between calculation model and visualization environment.

The multiple steps for the creation of the virtual models (buildings, streets, energy, ICT, pipelines, ...) especially the usage of various softwares for its handling, are improvable. A clear path for the development should be predefined and realized within one software package. Furthermore within the simulation environment some display and performance bugs based on mesh creation and UVshape-vector orientation have to be solved.

The interactive simultaneous use of the simulation environment within a backprojection (best visualized stereoscopic) environment enables a good laboratory for decision processes.

\section{Outlook}

The interweaving of interdisciplinary fields by visualizing their calculation and analysis output in a common simulation, generates new possibilities in urban developments. Urban structures include a broad range of objects with organic behaviour, always changing supply network (grid expansion, grid dismantling and new construction) and host users with a wide range of different interests, behaviours and goals. Nowadays data is generated and collected for most city objects (transport, people behaviour, electric demand, ...). Thus the city of information already exists. For the planning and sustainable management of the system city more information will be required so that more platforms can enable visual data views.

\section{Acknowledgements}

This project would have been impossible without the support of Wiener Stadtwerke Holding AG and the PhD program URBEM. Further thanks goes to Stefan Dürauer (MA 41) for providing the data sets on building solar potential registry and GIS buildings.

\section{References}

[1] Peter Prenner u.a., Stadtpunkte: Wien Wächst-Herausforderungen zwischen Boom und Lebensqualität: Tagungsband der AK-Wien Fachtagung. Kammer für Arbeiter und Angestellte Wien: Wien, 2014.

[2] Bernd Scholl, Thesen zur inneren Entwicklung unserer Städte und Regionen, in: Stadtgespräche, Veranstaltungsheft mit Unterstützung der Hamasil Stiftung. Veranstaltungsdurchführung: Institut für Raum- und Landschaftsentwicklung: Innenentwicklung vor Aussenentwicklung! IRL, ETH Zürich: Zürich, 2007. 
[3] ETH Zürich, Raum+: Initiative der Proffesur für Raumentwicklung ETH Zürich, http://www.raumplus.ethz.ch/home/.

[4] SmartUrbanAdapt, SUA - Smart Urban Adapt: Forschungsprojekt der ETH Zürich, Imperial College London, IBM, ESRI, 2012-2013.

[5] Cityzenith, Cityzenith: The Data Platform for the City.

[6] Walter Schönwandtd, e., disP - The Planning Review: Die Kunst des Problemlösens: Entwicklung und Evaluation eines Trainings im Lösen komplexer Planungsprobleme. (185), 2011.

[7] Stadtentwicklung Wien Magistratsabteilung 18 - Stadtentwicklung und Stadtplanung, STEP 2025 - Stadtentwicklungsplan Wien. Magistratsabteilung 18 - Stadtentwicklung und Stadtplanung: Vienna, 2014.

[8] Julia Forster, Sara Fritz, Nikolaus Rab, (ed.), Solar Heat Strategies For Vienna: Identifying Regions with Highly Reliable And Affordable Potential, 2015. 